\title{
Uso de geotecnologias na análise de focos de calor em uma sub-bacia do semiárido mineiro
}

\author{
Eduarda Soares Menezes ${ }^{1 *}$, Danielle Piuzana Mucida ${ }^{1}$, Luciano Cavalcante de Jesus França ${ }^{2}$, \\ Marcos Vinicius Miranda Aguilar ${ }^{3}$, Aline Ramalho dos Santos ${ }^{4}$, Daniela Torres Morandi ${ }^{1}$
}

\begin{abstract}
RESUMO: O trabalho teve como objetivo avaliar o uso de geotecnologias na análise espacial e temporal de focos de calor para a sub-bacia do rio Araçuaí, localizada no semiárido mineiro. O processamento foi realizado pelo uso do software QGIS 2.18.16, utilizando-se mapas em formato vetorial e calculada a densidade de Kernel para os anos de 2005, 2010, 2015 e 2017. Os resultados permitiram inferências sobre a distribuição dos registros de focos de calor, corroborando com a presença de incêndios em contraste com a situação ambiental das áreas. Os registros pertencentes as classes muito alta foram incidentes em região definida como áreas susceptíveis a desertificação. É evidente a necessidade de se ter a atenção voltada à fiscalização, principalmente nessas áreas de maior potencialidade à ocorrência de incêndios florestais. A metodologia empregada na pesquisa atendeu satisfatoriamente aos objetivos propostos, permitindo a indicação das áreas com predisposição a ocorrência de incêndios florestais, servindo como subsidio para aplicação dos procedimentos metodológicos em outras áreas da região semiárida brasileira.
\end{abstract}

Palavras-chave: Conservação, Incêndios florestais, Sistemas de informações geográficas

\section{Use of geotechnology in the analysis of heat foci in a sub-basin of mineiro semiarid}

\begin{abstract}
The objective of this study was to evaluate the use of geotechnologies in the spatial and temporal analysis of heat foci for the sub-basin of the Araçuaí River, it was located in the semi-arid region of Minas Gerais State. The processing was performed using the QGIS software 2.18.16, using maps in vector format and calculated the kernel density for the years 2005, 2010, 2015 and 2017. The results allowed inferences on the distribution of the records of foci of heat, corroborating with the presence of fires in contrast to the environmental situation of the areas. The records belonging to the very high classes were incident in a region defined as areas susceptible to desertification. It is evident the need to have the attention focused on the inspection, especially in these areas of greater potential to the occurrence of forest fires. The methodology employed in the research satisfactorily met the proposed objectives, allowing the indication of areas with predisposition to forest fires, serving as a subsidy for the application of methodological procedures in other areas of the Brazilian semiarid region.
\end{abstract}

Keywords: Conservation, Forest fires, Geographic information systems

\section{INTRODUÇÃO}

As sub-bacias hidrográficas influenciam no favorecimento dos aspectos geográficos e sociais ligados à organização comunitária, permitindo o gerenciamento simultâneo, e interdependente das condições ambientais, econômicas e sociais. Assim, as sub-bacias auxiliam não apenas na realização do planejamento, mas também na administração ligada aos recursos naturais, uma vez que abrangem também diferentes potencialidades dos processos operados (MORAIS et al., 2018).

O comportamento hidrológico das sub-bacias é influenciado por diversas características, como por exemplo, o relevo, área, rede de drenagem, solo, tipo da cobertura vegetal existente, dentre outros. Porém, esse comportamento também é afetado pelas ações antrópicas, visto que ao provocar uma intervenção no meio natural o homem interfere nos processos desse ciclo (FLORES, MISOCZKYET, 2015). Dentre as principais causas de degradação das subbacias destacam-se as ações ligadas às atividades antrópicas, como a ocupação desordenada nessas áreas, visando à expansão pecuária e produção agrícola, com isso, implica no aumento da frequência do fogo na região, e altera a capacidade de recuperação dos elementos da biota (NARDINI et al., 2015).

Nesse contexto, a ocorrência de incêndios florestais originados de forma natural ou antrópica podem se expandir de forma alarmante pela floresta, consumindo os diferentes tipos de combustíveis (DIOGENES et al., 2018), e possuir um alto potencial destrutivo sobre as diferentes áreas, e no

Recebido em 02/07/2018; Aceito para publicação em 30/04/2019

${ }^{1}$ Universidade Federal dos Vales do Jequitinhonha e Mucuri

2Universidade Federal de Lavras

3Instituto Federal de Educação Ciência e Tecnologia do Norte de Minas Gerais

4Universidade Federal do Espírito Santo

*E-mail: duda.engflorestal@gmail.com 
ecossistema de modo geral, implicando em impactos ambientais, sociais e econômicos (CHANG et al., 2015). Nota-se que os incêndios florestais geram problemas em várias escalas. Localmente, resulta na degradação da vegetação, promovem impactos na biodiversidade, e danos econômicos. De forma regional, a fumaça resulta em problemas para a saúde humana, e afeta os meios de transporte. Já em escala global, provocam aumento das emissões de carbono para a atmosfera, podendo resultar em consequências para o clima do planeta (ADÁMEK et al., 2015).

Mesmo que o incêndio seja considerado como parte da ecologia do cerrado, pesquisas evidenciam que o aumento da ocorrência do fogo provoca o baixo recrutamento de espécies lenhosas, gerando redução na densidade arbórea, aumento do entouceiramento de forrageiras, e diminuição da diversidade de espécies da fauna e flora. Além disso, contribuem para eliminação de espécies vegetais de baixa densidade, deixando as mesmas a deriva de agentes dispersores para se reestabelecerem novamente na área (MACHADO NETO et al., 2017).

Diante disso, faz-se necessário conhecer o histórico e o perfil dos incêndios, visto que, a compreensão do caráter estatístico, do tamanho, e da área de ocorrência dos incêndios florestais é extremamente relevante para os programas de proteção ambiental (IRLAND, 2013). Com esses dados, é possível planejar o controle de modo mais eficiente, uma vez que sem essas informações, podese subestimar ou superestimar os gastos referentes à proteção do meio ambiente, colocando em risco a sobrevivência das florestas (TORRES et al., 2016).

É amplamente reconhecido que o entendimento sobre o comportamento do fogo, e sua resposta às condições ambientais podem antecipar situações perigosas, ou impactos de grande magnitude (IRLAND, 2013). Assim, pesquisas sobre a incidência de focos de calor por meio do uso do geoprocessamento podem ser utilizadas como ferramenta metodológica para a execução de estudos que buscam o conhecimento da estrutura, dinâmica e função dos elementos da paisagem com o intuito de definir a espacialização de fenômenos como o risco aos incêndios (TORRES et al., 2017). Além disso, podem auxiliar nas medidas necessárias para a defesa contra os impactos relacionados às queimadas descontroladas por meio da geração de mapas temáticos estratégicos de combate ao incêndio, com a localização da rede viária, hidrografia, centros urbanos e também na obtenção de cartas de risco de incêndios (OLIVEIRA et al., 2017).

Os mapas de risco de incêndios originados através do SIG auxiliam os gestores no planejamento de forma estratégica das práticas de prevenção a longo prazo. Desse modo, o alongamento dos registros históricos, e mapas de ocorrência de focos de calor são indispensáveis, uma vez que, proporcionam uma melhor perspectiva sobre as mudanças reais no seu comportamento, e serve para a melhor compreensão da relação entre o fogo e clima (NICOLETE, ZIMBACK, 2013).

Diante disso, o trabalho teve como objetivo avaliar o uso de geotecnologias na análise espacial e temporal de focos de calor para a sub-bacia do rio Araçuaí, localizada no semiárido mineiro.

\section{MATERIAL E MÉTODOS}

\section{Área de estudo}

A área de estudo encontra-se inserida na bacia hidrográfica do rio Jequitinhonha, que possui delimitação federal. Ao norte limita-se com a bacia do rio Pardo, a sudeste com a bacia do Mucuri, e ao sul com a bacia do rio Doce, além de possuir diversas bacias pequenas independentes. Suas nascentes se encontram na Serra do Espinhaço Meridional, no município do Serro - MG, com uma altitude média de $1.300 \mathrm{~m}$.

A sub-bacia do rio Araçuaí localiza-se na porção sudeste da área da Bacia do Jequitinhonha (Figura 1). O rio Araçuaí é o principal afluente da margem direita do rio Jequitinhonha, possui extensão de 250 $\mathrm{km}$, e a sub-bacia apresenta uma área total de 16.343 $\mathrm{km}^{2}$, que abrange 19 municípios e abastece 23, representando cerca de 500 mil habitantes (DINIZ et al., 2015). O clima da bacia é considerado semiúmido, com período seco apresentando uma duração de quatro a cinco meses por ano (ROCHA, OLIVEIRA, 2017). Quanto a geologia, há um predomínio de afloramentos do embasamento arqueano, com algumas ocorrências de coberturas detríticas localizadas diretamente sobre essas. Neste caso, as coberturas detríticas aparecem nas extensões menores e alojadas imediatamente sobre as rochas predominantemente gnáissicas e graníticas, com uma cobertura dobrada de idade proterozoica, formada por rochas quatzíticas do Supergrupo Espinhaço, e também por rochas xistosas do Grupo Macaúbas (FERREIRA, 2007). 

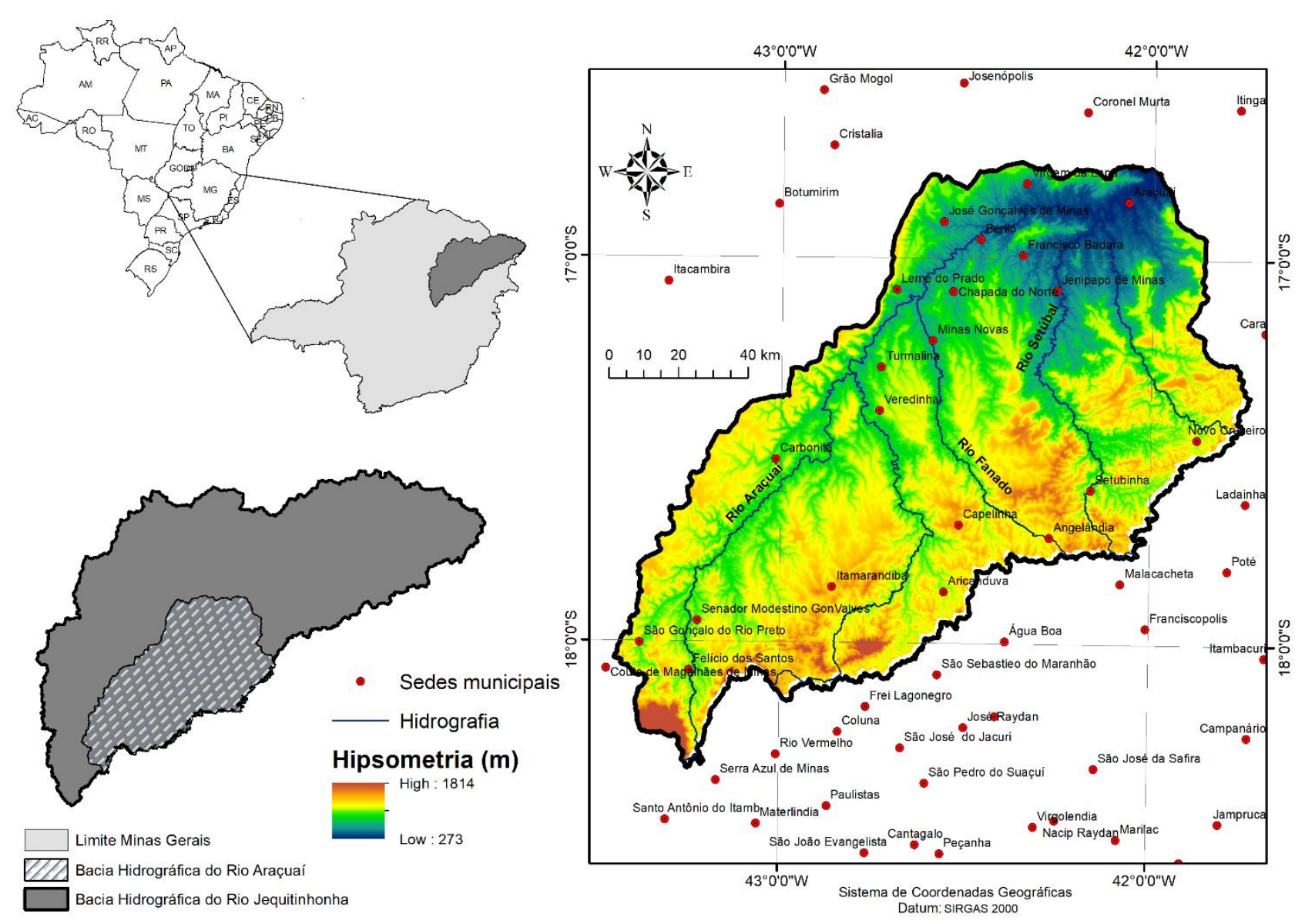

Figura 1 - Localização da sub-bacia do rio Araçuaí, bacia hidrográfica do rio Jequitinhonha.

\section{Análise dos dados}

A aquisição de dados sobre os focos de calor na sub-bacia do rio Araçuaí foi realizada por meio de arquivos vetoriais disponíveis na plataforma do banco de dados do Instituto Nacional de Pesquisas Espaciais (INPE), utilizando como referência o satélite AQUA_M-T, sensor MODIS (Moderate Resolution Imaging Spectroradiometer). A pesquisa foi embasada na sobreposição de imagens vetoriais com os registros dos focos de calor para todos os dias dos anos de 2005, 2010, 2015 e 2017.

Com o auxílio do software QGIS 2.18.16, foi possível realizar o processamento através da validação topológica das imagens, que em seguida foram sobrepostas utilizando os registros totais diários dos focos de calor na forma vetorial (shapefile) para cada ano de estudo. Nesse sentido, a escolha da região de interesse (Clip) foi executada, possuindo como suporte os limites disponibilizados na forma vetorial, com escala 1:100.000, retiradas do banco de dados do Instituto Pristino (INSTITUTO PRISTINO, 2018).

Depois de fazer a extração e geração das imagens preliminares, realizou-se a interpolação, sendo determinada a categoria de registros pontuais desses focos, com o cálculo de densidade através do estimador de Kernel:

$$
\lambda_{\tau}(\mathrm{S})=\sum_{\mathrm{i}=1}^{\mathrm{n}} \frac{1}{\tau^{2}} \mathrm{~K}\left(\frac{\left(\mathrm{S}-\mathrm{S}_{\mathrm{i}}\right)}{\tau}\right) \text { (Equação 1) }
$$

em que: $\mathrm{n}=$ contagem pontos amostrais (eventos); $\mathrm{K}=$ função de estimação de Kernel; $\tau=$ raio que determina grau de suavização; $\mathrm{S}_{\mathrm{i}}=$ localização inicial da superfície com o valor proporcional à intensidade dos eventos por unidade de área; $S=$ localização geral da superfície com o valor proporcional à intensidade dos eventos por unidade de área.

Mediante a análise, classificaram-se as densidades dos focos de calor em cinco níveis, sendo eles: muito baixa (100 -191 focos por $\mathrm{km}^{2}$ ), baixa (192 - 254 focos por $\mathrm{km}^{2}$ ), média (255 - 382 focos por $\left.\mathrm{km}^{2}\right)$, alta (383 - 763 focos por $\mathrm{km}^{2}$ ) e muito alta (764 - 1185 focos por $\mathrm{km}^{2}$ ), com pixel de $100 \mathrm{~m}$, e raio de $2000 \mathrm{~m}$.

\section{RESULTADOS E DISCUSSÃO}

Com o processamento dos registros e cálculos da densidade de Kernel, foi possível observar a distribuição espacial ao longo dos anos na sub-bacia Araçuaí (Figura 2). 


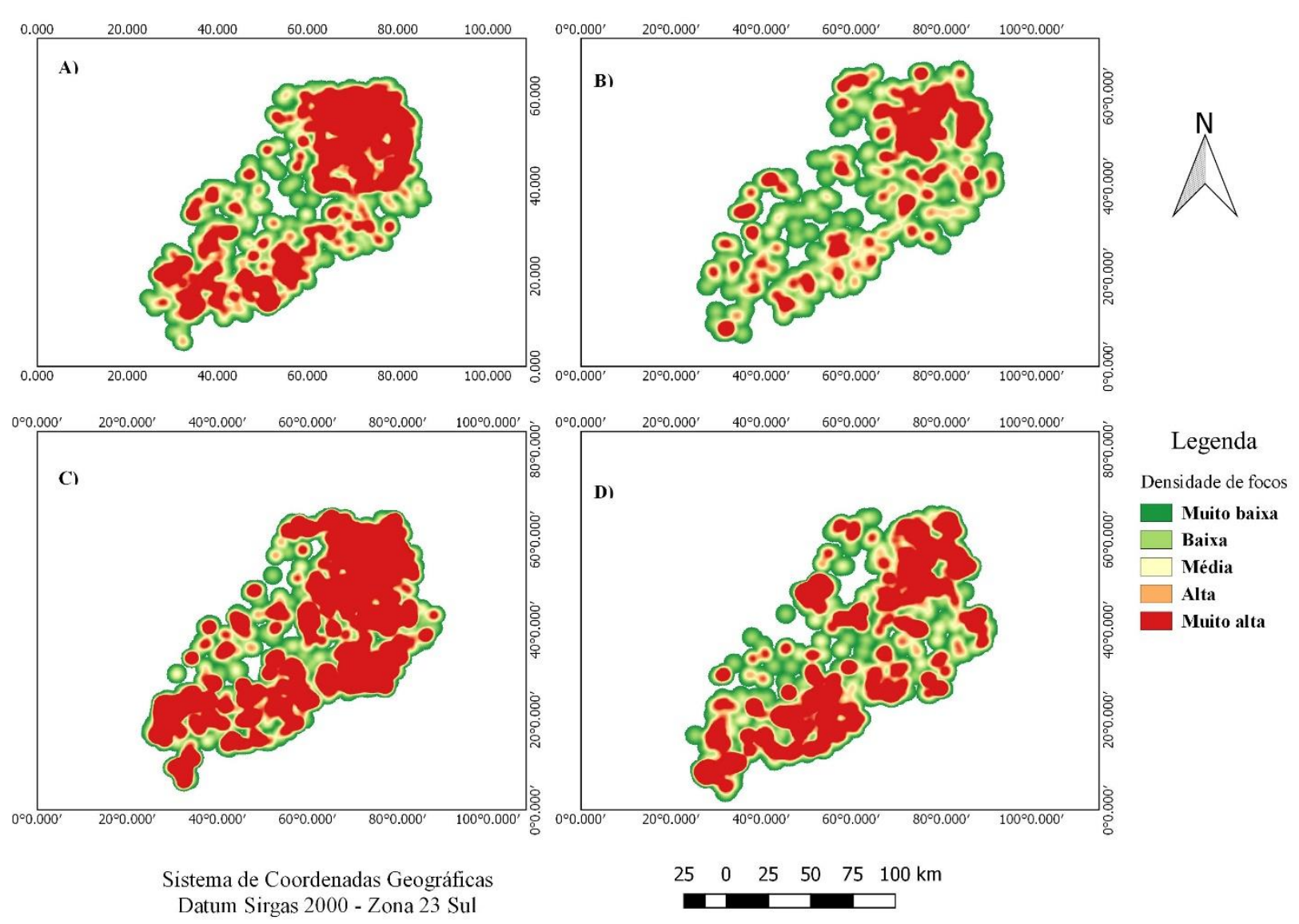

Figura 2 - Distribuição de focos de calor para a sub-bacia do rio Araçuaí: A) Ano de 2005; B) 2010; C) 2015 ; D) 2017.

Diante da classificação para o ano de 2005 (Figura 2A), evidencia-se uma amplitude da distribuição de registros nas classes Alta e Muito alta seguindo uma tendência Norte-Sul no território da bacia. Já em 2010 (Figura 2B), há uma diminuição marcante dessas classes nas áreas observadas no ano de 2005 (Figura 2A), entretanto, é nítida o registro de focos da classe Muito alta dispersos a norte, leste, centro e sul do terreno, sendo esses com intervalos maiores entre os raios. É marcante, ao analisar o ano de 2015 (Figura 2C), a abrangência expressiva em área e continuidade dos focos da classe Muito alto, seguindo uma tendência homogênea na maior parte da bacia. O ano de 2017 (Figura 2D), apresenta manchas maiores e dispersas a Norte, Centro e Sul com redução quando em comparada ao ano de 2015 (Figura 2C).

As áreas na sub-bacia que apresentam a classe Muito alta, consistem em regiões com declividade acentuada, conforme demonstrado a hipsometria demonstrada pela Figura 1, sendo áreas que caracterizam-se por terrenos acidentados com exposições de solo e afloramento de rochas, estradas que moldam a direção e propagação dos incêndios florestais, caracterizando as manchas com raios maiores que evidenciam a ocorrência de queimas não controladas e incêndios nessas regiões.
A conformação topográfica e altimétrica são fatores decisivos para a distribuição irregular das chuvas e determinante para os processos termodinâmicos no interior da bacia hidrográfica do rio Jequitinhonha, fator esse que pode ser relacionado com as incidências altas e muito altas de focos de calor em áreas de altitude elevada (SILVA, FERREIRA, 2011).

Há também, a existência de focos de calor da classe Muito Alta na parte de menores cotas altimétricas da sub-bacia entre municípios de Francisco Badaró, Berilo, Jenipapo de Minas e Araçuaí, porção mais setentrional da sub-bacia, que encontram-se em região definida como áreas susceptíveis a desertificação (ASD) do Subúmido de Minas Gerais, segundo o PAN Brasil (2004), perfaz uma superfície total de 79 mil $\mathrm{km} 2$, onde estão inseridos 61 municípios situados na região do Norte de Minas e Jequitinhonha (SEDVAN, 2010).

O semiárido do Vale do Jequitinhonha em Minas Gerais, caracteriza-se pela irregularidade na distribuição espacial e temporal das precipitações pluviométricas. Esse aspecto, associado às elevadas temperaturas registradas ao longo do ano e à prática da agricultura familiar intensiva, contribuem para a ocorrência de incêndios florestais, o que ressalta a atenção para essa região, por meio de estudos e 
aplicação de procedimentos metodológicos para o monitoramento e prevenção.

A discrepância entre os anos de 2010 e 2015, marcados por registros mais acentuados na classe Muito alta, é explicado por temperaturas médias acentuadas, umidade baixa e presença de material combustível proveniente da biomassa formada pela retirada de gramíneas (INMET, 2018).

Muitos dos registros averiguados, ocorrem em áreas com fragilidade ambiental acentuada, evidenciando a atuação dos fatores de degradação sobre esses ambientes, servindo de alerta para monitoramento e contenção de práticas não controladas e atuação eficiente dos órgãos ambientais.

Como observado em França (2018), os sítios ao nordeste da bacia do rio Araçuaí apresentam elevadas taxas de fragilidade ambiental potencial, de média a muito alta, coincidindo com as mesmas áreas de ocorrência histórica constante de elevados focos de calor. Desta forma, considerando-se múltiplos fatores ambientais, é fortemente necessário a atenção no que concerne aos problemas de degradação de áreas associados à incêndios.

As análises mostram que as classes de maior perigo de ocorrência de incêndios (alta e muito alta), se mostraram predominantes no território da subbacia ao longo dos anos. Esses indícios corroboram com a situação ambiental da área, caracterizando uma situação com potencial de incêndio na subbacia hidrográfica. Dessa forma, fica evidente a necessidade de se ter a atenção voltada à fiscalização, principalmente nessas áreas de maior potencialidade à ocorrência de incêndios florestais.

\section{CONCLUSÕES}

A partir da análise da densidade focos de calor por meio da densidade de Kernel, obteve-se êxito na determinação dos anos com maior ocorrência de incêndios florestais, evidenciada pelas condições físicas e meteorológicas do ambiente.

A metodologia empregada na pesquisa atendeu satisfatoriamente aos objetivos propostos, permitindo a indicação das áreas com predisposição a ocorrência de incêndios florestais, servindo como subsidio para aplicação dos procedimentos metodológicos em outras áreas da região semiárida brasileira, contribuindo para o monitoramento e tomada de decisões em questões ambientais.

\section{AGRADECIMENTOS}

O presente trabalho foi realizado com apoio da Coordenação de Aperfeiçoamento de Pessoal de Nível Superior - Brasil (CAPES) - Código de Financiamento 001.

\section{REFERÊNCIAS BIBLIOGRÁFICAS}

ADÁMEK, M.; BOBEK, P.; HADINCOVÁ, V.; WILD, J.; KOPECKÝ, M. Forest fires within a temperate landscape: a decadal and millennial perspective from a sandstone region in Central Europe. Forest Ecology and Management, v.336, n. 1, p. 81-90, 2015.

BARBOSA, N. F. M.; STOSIC, B. F.; STOSIC, T.; LOPES, P. M.; MOURA, G. B. A.; MELO, J. S. P. Kernel smoothing dos dados de chuva no Nordeste. Revista Brasileira de Engenharia Agrícola e Ambiental, Campina Grande, v.18, n. 7, p. 742-747, 2014.

CHANG, Y.; ZHU, Z.; BU, R.; LI, Y.; HU Y. Environmental controls on the characteristics of mean number of forest fires and mean forest area burned (19872007) in China. Forest Ecology and Management, p. 13-21, 2015.

DINIZ, H. N.; PEREIRA, P. R. B.; PEREIRA, S. Y.; GUTJAHR, M. R.; TORRIGO, M. Utilização de curvas de depleção de rios para estimativa de parâmetros hidrodinâmicos de aquíferos freáticos: exemplo da bacia do rio Capivari, Centro-Sul do Estado de São Paulo, 2015.

DIÓGENES, F. E. G.; GUIMARÃES, P. P.; BOTREL, R. T. Ocorrência de incêndios florestais em Caicó e Natal -

RN. Agropecuária Científica no Semiárido, Patos, v.14, n. 1 , p. $80-84,2018$.

FLORES, R. K.; MISOCZKY, M. C. Dos antagonismos na apropriação capitalista da água à sua concepção como bem comum. Organizações \& Sociedade, Salvador, v. 22, n. 73 , p. 237-250, 2015.

FERREIRA, V. O. Paisagem, Recursos hídricos e desenvolvimento econômico na bacia do Rio Jequitinhonha, em Minas Gerais. 2007. 291 f. Tese (Doutorado em Geografia). Universidade Federal de Minas Gerais. Belo Horizonte, 2007.

FRANÇA, L. C. J. Fragilidade ambiental potencial da bacia hidrográfica do rio Jequitinhonha, Minas Gerais, Brasil. Dissertação de Mestrado (Programa de Pós-Graduação em Ciência Florestal) Universidade Federal dos Vales do Jequitinhonha e Mucurí - UFVJM. 114p., Diamantina, 2018.

INSTITUTO NACIONAL DE METEOROLOGIA (INMET). Banco de dados meteorológicos para ensino e pesquisa. Disponível em: $<$ http://www.inmet.gov.br/portal/index.php?r=bdmep/bd mep>. Acesso em 03 abr 2018.

INSTITUTO PRISTINO. Atlas Digital Geoambiental. Disponível em: <https://www.institutopristino.org.br/atlas/>. Acesso em 01 jul 2018. 
IRLAND, L. C. Extreme value analysis of forest fires from New York to Nova Scotia, 1950-2010. Forest Ecology and Management, v.294, n. 13, p. 150-157, 2013.

MACHADO NETO, A. P.; BATISTA, A. C.; BIONDI, D.; SOARES, R. V.; BATISTA, A. P. B. Incêndios florestais no Parque Nacional da Chapada dos GuimarãesMT entre 2005 e 2014. Revista Nativa, Sinop, v.5, n. 5, p.355-361, 2017.

MORAIS, J. L. M;. FADUL, É.; CERQUEIRA, L. S. Limites e desafios na gestão de recursos hídricos por comitês de bacias hidrográficas: Um estudo nos estados do nordeste do Brasil. Revista eletrônica de Administração, Porto Alegre, v.24, n. 1, p. 238-264, 2018.

NARDINI, R. C.; CAMPOS, S.; RIBEIRO, F. L.; GOMES, L. N,; FELIPE, A. C.; CAMPOS, M. Avaliação das áreas de conflito de uso em APP da microbacia do ribeirão Morro Grande. Caminhos de Geografia, Uberlândia, v.16, n. 55, p. 104-113, 2015.

NICOLETE, D. A. P.; ZIMBACK, C. R. L. Zoneamento de risco de incêndios florestais para a fazenda experimental Edgardia - Botucatu (SP), através de sistemas de informações geográficas. Revista Agrogeoambiental, Pouso Alegre, v.5, n. 3, p. 55-62, 2013.

OLIVEIRA, A. L. S.; NERO, M. A.; TAVARES JÚNIOR, J. R.; CANDEIAS, A. L. B.; NÓBREGA, R. A. A. Comparação e validação da modelagem espacial de riscos de incêndios considerando diferentes métodos de predição. Bull. Geod. Sci, Articles Section, Curitiba, v. 23, n. 4, p. 556-577, 2017.

ROCHA, D. M.; OLIVEIRA, V. T. Análise da bacia hidrográfica do Rio Araçuaí/Minas Gerais para quantificação de redes de drenagens com uso de geotecnologias. In: Anais do XXVII Congresso Brasileiro de Cartografia e XXVI Exposicarta, 2017. Rio de Janeiro. Anais... Rio de Janeiro, 2017.

SEDVAN. Secretaria de Estado Extraordinária para o Desenvolvimento dos Vales do Jequitinhonha e Mucuri e do Norte de Minas. Plano de Ação Estadual de Combate à Desertificação e Mitigação dos Efeitos da Seca de Minas Gerais- PAE- MG. Belo Horizonte, 2010 .

SILVA, M. M.; FERREIRA, V. de O. Análise comparativa do clima de Araçuaí, Pedra Azul e Itamarandiba, na porção mineira da bacia do rio Jequitinhonha. Revista Caderno de Geografia, v.21, n.35, 2011.

TORRES, F. T. P.; LIMA, G. S.; COSTA, A. G.; FÉLIX, G. A.; SILVA JÚNIOR, M. R. Perfil dos incêndios florestais em unidades de conservação brasileiras no período de 2008 a 2012. Floresta, Curitiba, v.46, n. 4, p. 531-542, 2016.

TORRES, F. T. P.; ROQUE, M. P. B.; LIMA, G. S.; MARTINS, S. V.; FARIA, A. L. L. Mapeamento do Risco de Incêndios Florestais Utilizando Técnicas de Geoprocessamento. Revista Floresta e Ambiente, Seropédica, v.24, p 1-10, 2017. 